\title{
Evaluasi Tata Kelola Guna Meningkatkan Kinerja Manajemen Teknologi Informasi Menggunakan Framework COBIT 5
}

\author{
http://dx.doi.org/10.28932/jutisi.v7i1.3260 \\ Riwayat Artikel \\ Received: 7 Januari 2021 | Final Revision: 2 Maret 2021 | Accepted: 16 Maret 2021 \\ Fitria Febriani $^{\bowtie \# 1}$, Augie David Manuputty ${ }^{* 2}$ \\ Jurusan Sistem Informasi ${ }^{1}$,Universitas Kristen Satya Wacana ${ }^{1}$ \\ Jalan Diponegoro No. 52 - 60 Salatiga, Jawa Tengah \\ 1682017041 estudent.uksw.edu \\ Staf Pengajar Fakultas Teknologi Informasi ${ }^{2}$, Universitas Kristen Satya Wacana ${ }^{2}$ \\ Jalan Diponegoro No. 52 - 60 Salatiga, Jawa Tengah \\ 2augie.manuputty@uksw.edu
}

\begin{abstract}
The Salatiga Class I District Court is a government agency that has implemented Information Technology (IT) governance which has problems in IT management, so the purpose of this study is to evaluate information technology governance using the COBIT 5 framework by determining the level of capability and gaps. The results of the recapitulation of the questionnaire with the Likert scale model obtained the average value of the selected domain getting a value of 3.28 , which means that the current level of capability (as is) is at level 3 (established process), while the numbers from the range of 0 to 5 levels are expected or target (to be) namely 5 (optimization process). So that a gap or gap is obtained, namely the value of 1.27 which results in a reduction between to be and as is. The selected process domain is in the highest position, namely DSS01 with a value of 3.80 or level 4 (predictable process) while the lowest position is APO12 with a value of 2.82 or level 3 (established process). To achieve the expected conditions, the IT subdivision can improve in dealing with IT risks and IT problems that occur in the Salatiga District Court Class I B. In addition to evaluating IT governance, testing system functionality is also carried out by using the Blackbox Testing method with the Boundary Value Analysis technique. The object is used for testing the system, namely e-Court tested on the registration page and login page. From the results of system testing e-Court On the registration page, there is a discrepancy in the expected name Field and on the login page that the test results Field - Field as expected.
\end{abstract}

Keywords - Information Technology Governance; COBIT 5; e - Court; Blackbox Testing; Boundary Value Analysis.

\section{Pendahuluan}

Semakin berkembangnya revolusi teknologi yang sangat pesat khususnya pada Teknologi Informasi (TI) dan komputer, menyebabkan suatu organisasi perusahaan maupun instansi pemerintahan mengerti arti penting TI dalam menjalankan proses bisnisnya. Secara global, instansi pemerintahan sekarang ini menerapkan TI untuk membantu dalam menjalankan proses bisnis yang berdampak positif sehingga mampu mencapai visi dan misi serta dapat meningkatkan mutu pelayanan dan kinerja sumber daya yang baik. Pemanfaatan TI di dalam instansi pemerintahan terutama pada bidang perkara tidak hanya digunakan oleh pegawai yang bekerja di bagian TI saja, tetapi menjadi keharusan bagi pegawai yang bekerja pada semua bagian seperti bagian administrasi, keuangan, pidana, perdata dan lain - lain yang berkaitan dengan TI [1]. Dengan menerapkan TI di instansi pemerintahan dalam bidang perkara memiliki Sistem Informasi (SI) yang digunakan sebagai manajemen pengambilan keputusan dan menjalankan operasional yang terorganisir. Penerapan TI dibutuhkan tata kelola TI yang biasanya dikenal sebagai IT Governance yang bertujuan untuk mempertahankan dan meningkatkan nilai stakeholder, mengoptimalisasi sumber daya dan dapat mengatasi risiko serta mengembangkan TI yang ada. Perlu tata kelola TI yang baik, dilakukan pengembangan tata kelola TI dengan mengevaluasi kinerja TI menggunakan kerangka kerja / framework COBIT, ISO, ITIL, TOGAF dan lain - lain.

Pengadilan Negeri Salatiga Kelas I B adalah suatu instansi pemerintahan yang telah menerapkan Teknologi Informasi (TI) dengan memiliki banyak sistem perangkat lunak berbasis website yang digunakan untuk memaksimalkan suatu informasi dalam menjalankan operasionalnya. Sistem perangkat lunak yang diutamakan saat ini di Pengadilan Kelas I B Salatiga yaitu Sistem Informasi Penelusuran Perkara (SIPP) dan $e-$ Court. SIPP berfungsi sebagai 
manajemen seluruh data perkara, sedangkan $e$ - Court berfungsi untuk mempermudah dalam proses pelayanan pendaftaran perkara dalam penggugatan serta dapat melakukan pembayaran, pemanggilan dan persidangan secara online. Namun, terdapat kendala dan masalah dalam pengelolaan TI yaitu pada penggunaan infrastruktur TI belum maksimal seperti koneksi server yang sering putus, bagian pengelolaan TI belum menangani secara maksimal jika terjadi kerusakan atau masalah, kurangnya teknis persiapan penggunaan sistem terutama $e$ - Court, dan beberapa sistem masih pada tahap pengembangan serta Pengadilan belum pernah dilakukan evaluasi atau audit pada pengelolaan TI dengan menggunakan kerangka kerja / framework tertentu.

Tujuan penelitian ini yaitu untuk mengevaluasi kinerja tata kelola TI di Pengadilan Negeri Salatiga Kelas I B agar dapat mengetahui seberapa besar kinerja TI dengan menerapkan kerangka kerja / framework COBIT 5 dan melakukan pengujian fungsionalitas pada sistem $e$-Court karena sistem tersebut sistem yang mempunyai banyak permasalahan. COBIT 5 ini dipilih karena merupakan kerangka kerja yang sempurna sehingga dapat membantu perusahaan dalam mencapai tujuan untuk tata kelola dan manajemen TI dengan proses domain yaitu Evaluate, Direct and Monitor (EDM), Align, Plan and Organize (APO), Build, Acquire and Implement (BAI), Deliver, Service and Support (DSS) dan Monitor, Evaluate and Assess (MEA) [2]. Untuk memastikan $e$-Court memiliki fungsionalitas yang baik maka dilakukan pengujian perangkat lunak karena pengujian ini memiliki peran penting dalam suatu sistem informasi, dengan pengujian ini dapat diketahui cacat atau error yang akan muncul pada perangkat lunak [3]. Metode yang digunakan dalam pengujian $e-$ Court yaitu menggunakan Blackbox Testing dengan teknik Boundary Value Analysis sehingga, dengan adanya Blackbox Testing dapat membuat suatu keadaan dimana menginput data di dalam perangkat lunak yang akan melatih atau menguji dari seluruh syarat-syarat fungsionalnya [4]. Dengan menggunakan penelitian ini dihasilkan nilai tingkat kapabilitas, analisis kesenjangan, hasil pengujian perangkat lunak dan dapat merekomendasikan yang diberikan kepada pihak Pengadilan Negeri Salatiga Kelas I B.

\section{TINJAUAN PUSTAKA}

Penelitian sebelumnya terkait dengan penggunaan framework COBIT 5 pada tata kelola TI yang dilakukan oleh Elly dan Fandi Halim tentang "Evaluasi Tata Kelola Infrastruktur TI dengan Framework COBIT 5 (Studi Kasus : STMIK - STIE MISKROSKIL)" mengatakan, TI menjadi bagian penting dari organisasi. STMIK - STIE MISKROSKIL memiliki sebuah bagian yaitu pusat sistem informasi yang bertugas dalam melaksanakan sistem informasi, pengembangan, implementasi dan perawatan perangkat keras serta perangkat jaringan komputer. Departemen TI saat ini sering menghadapi masalah seperti infrastruktur TI yang ada tidak sesuai strategi bisnis STIE
MISKROSKIL sehingga menjadi sumber masalah dalam pengelolaan TI. Masalah yang terjadi pada infrastruktur TI yaitu minimnya maintenance karena anggaran pada organisasi terbatas sehingga infrastruktur TI tidak dapat digunakan dalam waktu jangka lama. Maka dilakukan evaluasi tata kelola pada infrastruktur TI menggunakan COBIT 5 sebagai kerangka kerja untuk mengevaluasi tata kelola infrastruktur TI. Proses yang dipilih berdasarkan pemetaan COBIT 5 Process terhadap IT-Related Goals pada STMIK - STIE MISKROSKIL yaitu EDM01, EDM02, EDM04, APO01, APO03, APO04, APO07, BAI02, DSS05, dan MEA01. Dari proses domain yang disebutkan sebelumnya dievaluasi dan menghasilkan bahwa proses domain dengan perhitungan capability level pada saat ini adalah 2,30 dimana hasil perhitungan kemudian terdapat kesenjangan sebesar 1,70. Sedangkan target pencapaian yang ditetapkan Mikroskil adalah 4. Untuk menutupi kesenjangan yang ada pada infrastruktur TI STMIK-STIE Mikroskil diperlukan rekomendasi agar mencapai target capability level [5].

Berdasarkan penelitian dari Yusra Fernando, Rayin Bi Ilmillah dan Dedi Darwis yang telah dilakukan tentang "Audit Kinerja Sistem Informasi Penelusuran Perkara Pada Pengadilan Agama Tanjung Karang Kelas I A Bandar Lampung", mengatakan bahwa manfaat TI dapat memberikan nilai bagi stakeholder di dalam perusahaan. Pengadilan Agama Tanjung Karang Kelas I A Bandar Lampung telah menggunakan TI yaitu memiliki Sistem Informasi Penelusuran Perkara (SIPP) yang berfungsi untuk mengolah data perkara. SIPP belum diketahui apakah sistem ini telah mencapai visi dan misi perusahaan serta terjaminya kerahasiaan dan keamanan data yang harus dikirim ke pusat untuk dimonitoring. Sehingga dilakukan audit sistem menggunakan COBIT 5 fokus pada domain EDM03, APO01, APO11, APO12, BAI06, DSS01, DSS02, DSS03, DSS05, MEA01 dan MEA01. Hasil audit yang telah dilakukan pada tingkat kapabilitas mencapai angka 3,7 dari nilai 0 sampai 5 yang artinya Pengadilan Agama Tanjung Karang Kelas I A Bandar Lampung telah memiliki pengawasan terhadap proses TI guna mengurangi berbagai macam kinerja proses sehingga pengembangan proses dapat diukur dengan limit namun harus dilakukan secara hati - hati. Untuk memenuhi kekurangan proses domain yang terpilih dapat diberikan rekomendasi agar target yang diinginkan tercapai [6].

Kemudian penelitian lainnya pernah dilakukan oleh Aang Kisnu Darmawan dan Arisandi Dwiharto dengan judul "Pengukuran Capability Level Kualitas Layanan EGovernment Kabupaten Pamekasan Menggunakan Framework COBIT 5.0", e-Government adalah proses pemanfaatan TIK yang dapat membantu dalam proses sistem pemerintahan secara efisien dan transparan. Kabupaten Pamekasan dan Pemerintah Daerah lain sedang menghadapi kesulitan dalam menerapkan e-Government karena pada perencanaan pengembangan e-Government belum pernah dilakukan secara integral dan komprehensif dengan melibatkan semua pihak, instansi dan stakeholder. Hal ini 
menjadi kendala dalam mewujudkan visi dan misi Kabupaten Pamekasan menjadi Kota Digital / Cyber City. Perlu penerapan tata kelola layanan TIK yang baik menuju Good Governance yang transparan, akuntabel dan efektif, maka dilakukan audit atau evaluasi terhadap tata kelola layanan TIK di Dispendukcapil Kabupaten Pamekasan menggunakan framework COBIT 5 pada proses domain EDM dan APO. Kemudian hasil audit pada tata kelola layanan TIK di Dispendukcapil Kabupaten Pamekasan dalam hasil pengukuran capability level berada pada level 3 yang artinya semua proses layanan TIK sudah terlaksanakan sesuai standar layanan TIK yang berlaku. Dengan rincian pada domain EDM capability level menghasilkan angka 2,78, domain APO capability level menghasilkan angka 2,50. Saran dan rekomendasi yang bisa dilakukan adalah meningkatkan tata kelola layanan TIK dengan menambah kompetensi dan pengetahuan dalam bidang TIK pada Sumber Daya Manusia [7].

\section{LANDASAN TEORI}

\section{A. Tata Kelola Teknologi Informasi}

Konsep Tata Kelola TI (IT Governance) adalah bagaimana cara mengelola penggunaan TI disebuah perusahaan dengan menggabungkan antara perencanaan dan pengorganisasian, pembangunan dan pengimplementasian, pengiriman dan dukungan serta memonitor kinerja sistem informasi untuk memastikan TI dapat mendukung visi dan misi perusahaan [8].

Tata Kelola TI bertujuan untuk mengarahkan dan mengelola TI agar dapat memastikan bahwa kinerja TI dapat memenuhi visi dan misi perusahaan [9] :

1) Menyelaraskan investasi dan prioritas TI dengan bisnis.

2) Mengelola, mengevaluasi, memprioritaskan, menganggarkan, mengukur, dan mengawasi permintaan untuk layanan TI.

3) Memanfaatkan sumber daya dan aset dengan cara bertanggung jawab dan efisien.

4) Memastikan TI dapat memenuhi perencanaan, anggaran dan komitmen.

5) Menetapkan dan menjelaskan dengan jelas mendefinisikan peran dan kewenangan serta dan hak mengambil keputusan.

6) Mengelola risiko dan perubahan.

7) Meningkatkan kinerja tim TI, kepatuhan, kematangan dan pengembangan staf.

8) Meningkatkan layanan pelanggan dan daya tanggap secara keseluruhan.

\section{B. COBIT 5}

Menurut ISACA, COBIT 5 adalah salah satu kerangka kerja yang komprehensif dapat membantu perusahaan dalam mencapai tujuan mereka untuk tata kelola dan manajemen TI perusahaan. Kerangka kerja (framework) COBIT 5 dapat membantu perusahaan dalam menciptakan nilai TI yang optimal dengan cara menjaga keseimbangan seperti mewujudkan manfaat TI, mengoptimalkan tingkat risiko dan mengoptimalkan penggunaan sumber daya. Model COBIT 5 ini adalah penerus dari COBIT 4, Risiko TI dan VA - IT [2]. Kerangka kerja ini ditujukan semua perusahaan termasuk non-profit dan sektor publik [10].

COBIT 5 memiliki proses tata kelola dan manajemen TI perusahaan yang terbagi menjadi dua bagian utama proses domain yaitu Governance dan Management yang dapat dilihat pada gambar 1 [2].

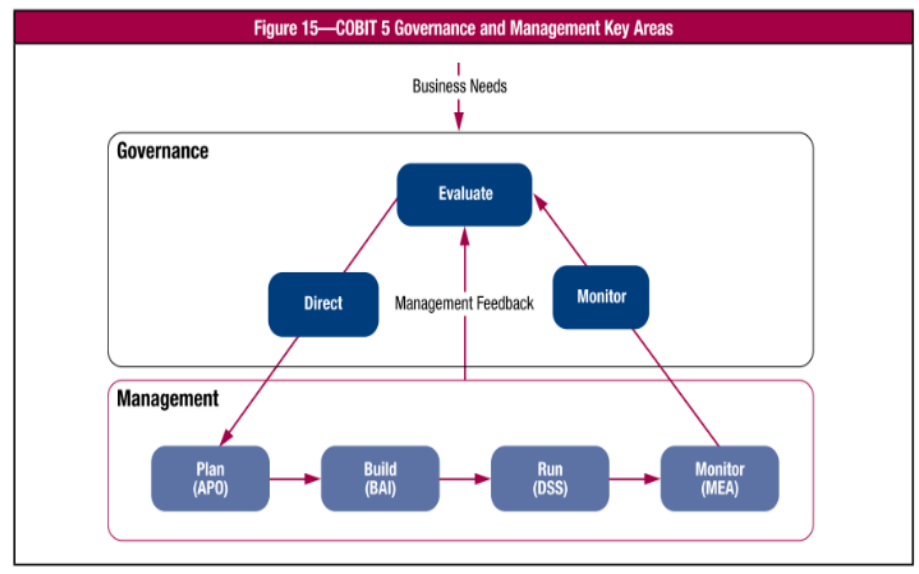

Gambar 1. COBIT 5 Governance and Management Key Areas

Proses tata kelola dan manajemen pada COBIT 5 memiliki 37 proses yang terdapat pada 5 domain yang terdiri dari :

1) Governance

Memiliki 5 proses pada domain Evaluate, Direct And Monitor (EDM).

2) Management

- Memiliki 13 proses pada domain Align, Plan and Organise (APO).

- Memiliki 10 proses pada domain Build, Acquire and Implement (BAI).

- Memiliki 6 proses pada domain Deliver, Service and Support (DSS).

- Memiliki 3 proses pada domain Monitor, Evaluate and Assess (MEA).

COBIT 5 memiliki langkah - langkah dalam menentukan domain proses dengan mengidentifikasikan tujuan bisnis dan tujuan TI ke dalam COBIT seperti pada gambar 2 . 


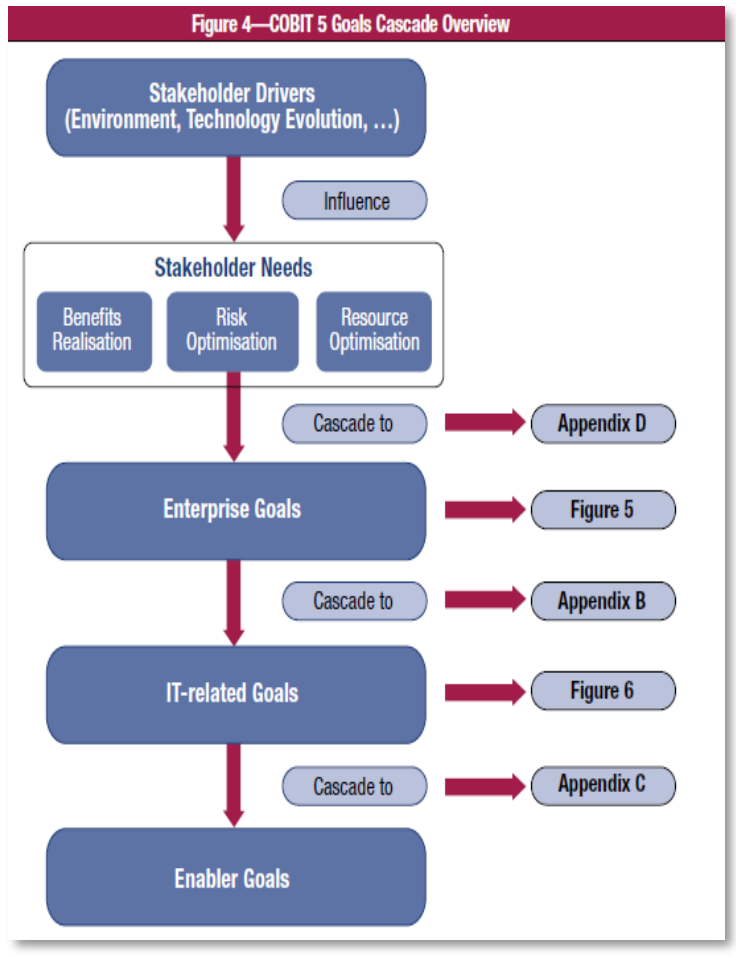

Gambar 2. COBIT 5 Goals Cascade Overview

Menurut ISACA pada COBIT 4.1 terdapat Process Maturity Model atau Kematangan Proses, sedangkan COBIT 5 terdapat Process Capability Model atau Kapabilitas Proses. Pada Process Capability Model di COBIT 5 didasari oleh ISO/IEC 15504 Software Engineering dengan standar Process Assessment. Model ini akan mencapai tujuan keseluruhan yang sama dari penilaian proses dan dukungan peningkatan proses untuk mengukur kinerja proses tata kelola dan manajemen. Pendekatan penilaian kapabilitas proses yang terkandung pada COBIT 5 disebut dengan Process Assessment Model (PAM). Kapabilitas proses pada setiap tingkat mempunyai Process Attribute (PA) yang terdiri enam tingkat yaitu [2] :

- Level 0 : Incomplete Process

- $\quad$ Level 1 : Performed Process

PA 1.1 Process Performance Attribute

- $\quad$ Level 2 : Managed Process

PA 2.1 Performance Management

PA 2.2 Work Product Management

- Level 3 : Established Process

PA 3.1 Process Definition

PA 3.2 Process Deployment

- $\quad$ Level 4 : Predictable Process

PA 4.1 Process Measurement

PA 4.2 Process Control

- $\quad$ Level 5 : Optimising Process

PA 5.1 Process Innovation

PA 5.2 Process Optimization
Enam tingkat kapabilitas proses yang disebutkan di atas dapat dijelaskan sebagai berikut [2] :

- Level 0 : Proses tidak lengkap

Proses yang gagal atau tidak dilakukan dalam mencapai tujuan prosesnya. Pada tingkat ini ada sedikit atau tidak ada bukti pencapaian secara sistematis dari tujuan proses.

- Level 1 : Proses yang dilakukan

Proses yang diimplementasikan untuk mencapai tujuan prosesnya.

- $\quad$ Level 2 : Proses yang dikelola

Proses yang berhasil dikelola dengan cara direncanakan, dipantau, dan disesuaikan.

- Level 3 : Proses yang ditetapkan

Proses terkelola akan ditentukan atau ditetapkan sehingga dapat mampu mencapai hasil prosesnya.

- $\quad$ Level 4 : Proses yang diprediksi

Proses yang ditetapkan sekarang beroperasi dalam batas yang ditentukan atau diprediksi untuk mencapai hasil prosesnya.

- Level 5 : Proses pengoptimalan

Proses yang dapat diprediksi terus ditingkatkan atau dioptimalkan untuk memenuhi tujuan bisnis yang relevan saat ini dan yang diproyeksikan.

\section{E-Court}

E - Court adalah sistem pelayanan masyarakat di Pengadilan dalam hal pendaftaran perkara, pembayaran $(e-$ Payment), pengiriman dokumen persidangan (seperti : Replik, Duplik, Kesimpulan dan Jawaban) dan pemanggilan ( $e$ Summons) secara online. Keuntungan dalam memakai $e-$ Court yaitu [11]:

1) Menghemat waktu dan biaya dalam proses pendaftaran.

2) Pembayaran biaya yang dapat dilakukan dalam metode pembayaran dengan melewati bank.

3) Dokumen arsip yang tersusun baik dan dapat diakses dimana saja.

4) Pencarian data yang lebih cepat.

\section{Blackbox Testing}

Blackbox testing adalah metode untuk menguji perangkat lunak atau sistem yang berfokus pada fungsional. Tujuannya dalam menguji sistem perangkat lunak menggunakan blackbox testing ini agar sistem dapat dikembangkan. Blackbox testing digunakan untuk menemukan permasalahan yaitu [12] :

- Fungsi salah atau hilang.

- Kesalahan pada interface.

- Kesalahan struktur data dan basis data.

- Kesalahan fungsi pada performasi.

- Kesalahan deklarasi dan terminasi. [13] : 
- Equivalence Partitioning.

- Boundary Value Analysis/Limit Testing

- Comparison Testing.

- Sample Testing.

- Robustness Testing

- Behavior Testing

- Requirement Testing

- Performance Testing

- Uji Ketahanan (Endurance Testing)

- Uji Sebab-Akibat (Cause-Effect Relationship Testing)

\section{E. Boundary Value Analysis}

Boundary value analysis adalah teknik mengukur kualitas perangkat lunak apabila ada kesalahan saat memasukan data yang akan diuji pada suatu kolom ditentukan nilai tersebut telah valid atau tidak valid, sehingga tidak ada lagi kesalahan yang akan tersimpan di database. Boundary value analysis digunakan untuk menentukan nilai batas atas dan batas bawah dengan melalui beberapa tahapan yang telah ditentukan [3].

\section{Metodologi Penelitian}

Metode penelitian yang digunakan yaitu metode kuantitatif yang dilakukan pengukuran tingkat kapabilitas dengan menghitung dari hasil kuesioner dan metode kualitatif yang diperoleh dari hasil wawancara serta diskusi dalam menyelaraskan tujuan organisasi dengan tujuan berdasarkan COBIT 5. Metode penelitian ini dapat dijelaskan dengan tahapan yang dapat dilihat pada gambar 3 .

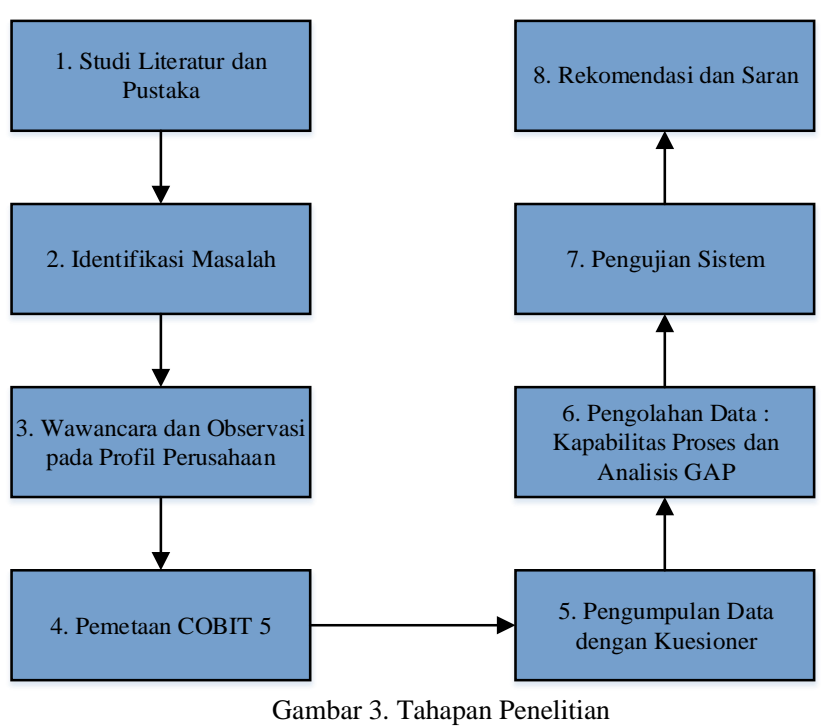

Pada tahapan penelitian mengacu pada kerangka kerja COBIT 5 yang dapat dijelaskan sebagai berikut :

1) Objek penelitian di Pengadilan Negeri Salatiga Kelas I B dipilih karena mewakili instansi pemerintahan dibidang hukum yang menerapkan teknologi informasi sehingga dapat dilakukan evaluasi tata kelola TI yang dijadikan topik penelitian.

2) Melakukan studi literatur dan studi pustaka sebagai dasar referensi penelitian.

3) Mengindentifikasi masalah dilakukan untuk mendapatkan permasalahan mengenai TI yang terjadi di Pengadilan Negeri Salatiga Kelas I B.

4) Wawancara dan observasi pada profil perusahaan seperti visi, misi, tujuan dan struktur organisasi serta peran dan tanggung jawab tiap pegawai.

5) Melakukan proses analisis :

- Identifikasi Enterprise Goals COBIT 5 terpilih berdasarkan dari visi, misi dan kebijakan mutu Pengadilan Negeri Salatiga Kelas I B.

- Pemetaan Enterprise Goals to IT - Related Goals COBIT 5 terpilih menggunakan dua kategori yaitu Primary (P) dan Secondary (S).

- Pemetaan IT - Related Goals to Process COBIT 5 terpilih menggunakan dua kategori yaitu Primary (P) dan Secondary (S).

6) Pengambilan data dilakukan dengan penyebaran kuesioner dengan model skala likert dimana responden terpilih berdasarkan analisis RACI Chart.

7) Dalam menentukan tingkat kapabilitas dilakukan dengan merekapitulasi jawaban responden dari kuesioner model skala likert. Skala likert adalah suatu skala yang digunakan di dalam kuesioner dan merupakan salah satu teknik evaluasi disuatu program untuk mengukur pendapat dan sikap dari seseorang [14].

Setelah menentukan nilai dan tingkat kapabilitas dapat ditentukan tingkat gap atau kesenjangan.

8) Melakukan pengujian sistem menggunakan metode Blackbox Testing dengan teknik Boundary Value Analysis.

9) Memberikan rekomendasi dan saran kepada objek penelitian untuk mengoptimalkan kinerja TI.

\section{HASIL DAN PEMBAHASAN}

\section{A. Identifikasi Enterprise Goals Terpilih}

Pada tahap ini visi, misi dan kebijakan mutu Pengadilan Negeri Salatiga Kelas I B diselaraskan dengan Enterprise Goals pada COBIT 5 menggunakan analisis Balanced Scrorecard (BSC) yang didalamnya memiliki empat perspektif yaitu Financial, Customer, Internal dan Learning \& Growth. Balanced Scrorecard (BSC) adalah suatu kerangka kerja yang dapat membantu dan mendukung sebuah organisasi dalam mengelola strategi perusahaan ke masa depan dengan lebih baik [15]. Pada tabel I ada dua kategori Primary $(\mathrm{P})$ yang diartikan memiliki keterhubungan yang tinggi antara Enterprise Goals dengan Governance Objectives sedangkan Secondary (S) yang diartikan memiliki keterhubungan yang rendah antara Enterprise Goals dengan Governance Objectives. Hasil dari identifikasi Enterprise 
Goals COBIT 5 dapat dilihat dengan adanya blok warna kuning yaitu yang terpilih dapat dilihat pada tabel I.

TABEL I

IDENTIFIKASI ENTERPRISE GOALS COBIT 5 TERPILIH

\begin{tabular}{|c|c|c|c|c|c|}
\hline \multirow[b]{2}{*}{ BSC Dimension } & \multirow{2}{*}{\multicolumn{2}{|c|}{ Enterprise Goals }} & \multicolumn{3}{|c|}{ Governance Objectives } \\
\hline & & & $\begin{array}{c}\text { Benefits } \\
\text { Realization }\end{array}$ & $\begin{array}{c}\text { Risk } \\
\text { Management }\end{array}$ & $\begin{array}{c}\text { Resource } \\
\text { Optimazation }\end{array}$ \\
\hline \multirow{5}{*}{ Financial } & 1 & Stakeholder value of business investments & $\mathbf{P}$ & & \\
\hline & 2 & Portfolio of competitive products and services & $\mathbf{P}$ & $\mathbf{P}$ & $\mathbf{S}$ \\
\hline & 3 & Managed business risk (safe guarding of assets) & & $\mathbf{P}$ & $\mathbf{S}$ \\
\hline & 4 & Compliance with external laws and regulations & & $\mathbf{P}$ & \\
\hline & 5 & Financial transparency & $\mathbf{P}$ & $\mathbf{S}$ & $\mathbf{S}$ \\
\hline \multirow{5}{*}{ Customer } & 6 & Customer-oriented service culture & $\mathbf{P}$ & & $\mathbf{S}$ \\
\hline & 7 & Business service continuity and availability & & $\mathbf{P}$ & \\
\hline & 8 & $\begin{array}{l}\text { Agile responses to a changing business } \\
\text { environment }\end{array}$ & $\mathbf{P}$ & & $\mathbf{S}$ \\
\hline & 9 & Information-based strategic decision making & $\mathbf{P}$ & $\mathbf{P}$ & $\mathbf{P}$ \\
\hline & 10 & Optimisation of service delivery costs & $\mathbf{P}$ & & $\mathbf{P}$ \\
\hline \multirow{5}{*}{ Internal } & 11 & Optimisation of business process functionality & $\mathbf{P}$ & & $\mathbf{P}$ \\
\hline & 12 & Optimisation of business process costs & $\mathbf{P}$ & & $\mathbf{P}$ \\
\hline & 13 & Managed business change programmes & $\mathbf{P}$ & $\mathbf{P}$ & $\mathbf{S}$ \\
\hline & 14 & Operational and staff productivity & $\mathbf{P}$ & & $\mathbf{P}$ \\
\hline & 15 & Compliance with internal policies & & $\mathbf{P}$ & \\
\hline \multirow{2}{*}{$\begin{array}{l}\text { Learning and } \\
\text { Growth }\end{array}$} & 16 & Skilled and motivated people & $\mathbf{S}$ & $\mathbf{P}$ & $\mathbf{P}$ \\
\hline & 17 & Product and business innovation culture & $\mathbf{P}$ & & \\
\hline
\end{tabular}

B. Mapping Enterprise Goals to IT-Related Goals

Pemetaan ini dilakukan dengan berdasarkan dua kategori yaitu Primary (P) yang menunjukan bahwa ada keterhubungan yang tinggi antara Enterprise Goals to IT dengan Related Goals, dan Secondary (S) menunjukan keterhubungan yang rendah antara Enterprise Goals to IT dengan Related Goals. Hasil pemetaan ini dapat dilihat pada Tabel II. 
TABEL II

MAPPING ENTERPRISE GOALS TO IT - RELATED GOALS COBIT 5

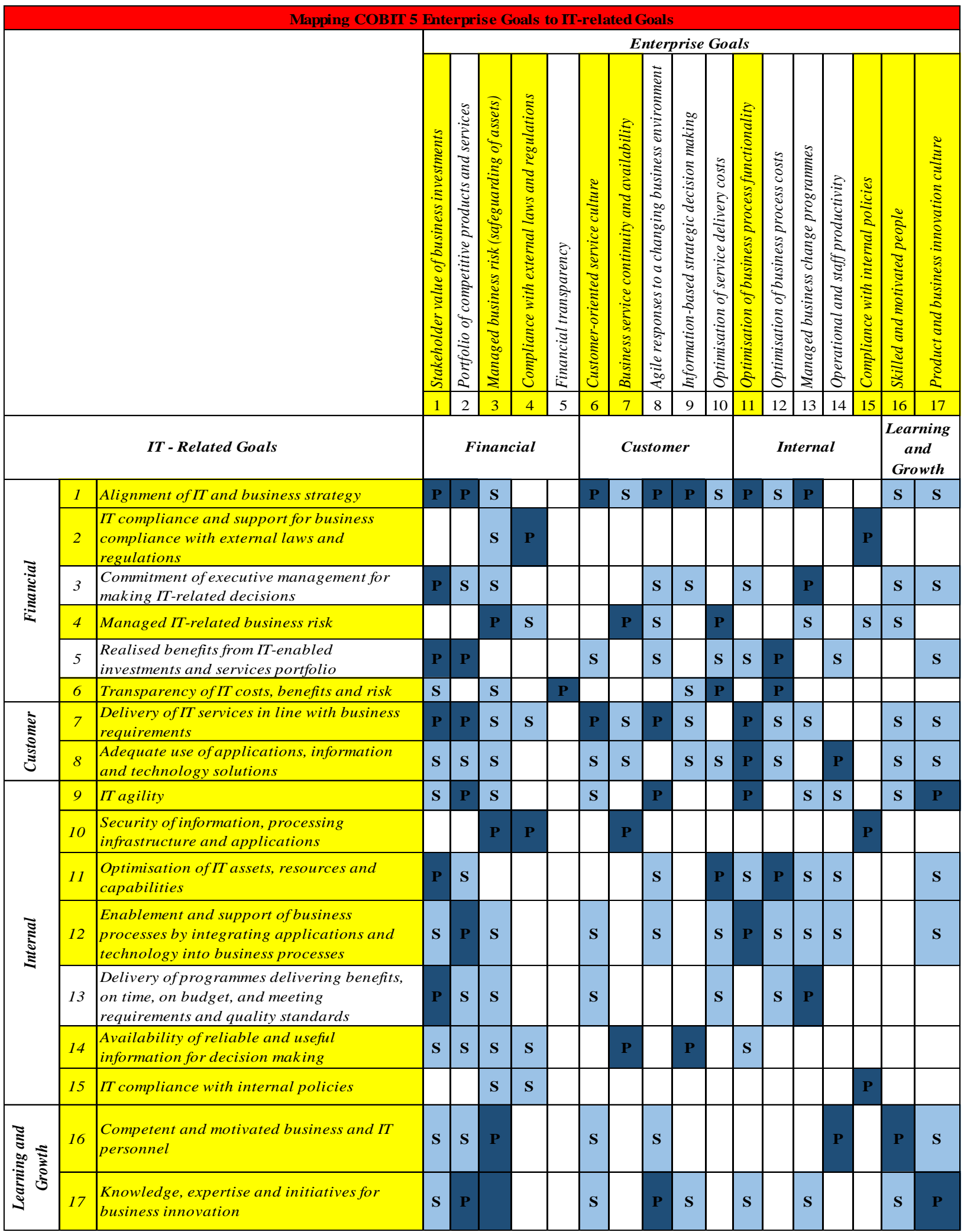




\section{Mapping IT - Related Goals to Process COBIT}

Pemetaan ini dilakukan setelah melakukan pemetaan antara Enterprise Goals dengan IT Related Goals, sehingga dapat menentukan domain COBIT 5 yang akan dipilih. Selain itu untuk menentukan domain COBIT 5, juga berdasarkan masalah - masalah terkait IT di Pengadilan Negeri Salatiga Kelas I B yang dapat dilihat pada tabel III.

TABEL III

MAPPING IT - RELATED GOALS TO PROCESS COBIT 5

\begin{tabular}{|c|c|c|c|c|c|c|c|c|c|c|c|c|c|c|c|c|c|c|c|}
\hline & & & \multicolumn{17}{|c|}{ IT - Related Goals } \\
\hline & & & 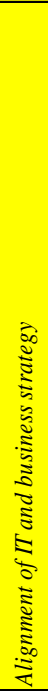 & 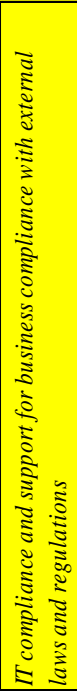 & 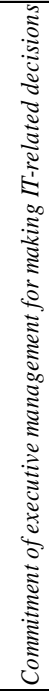 & 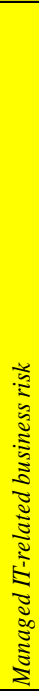 & 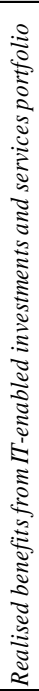 & 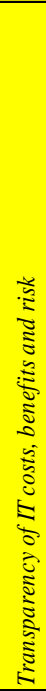 & 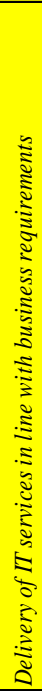 & 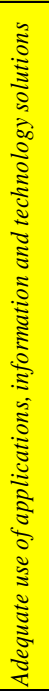 & 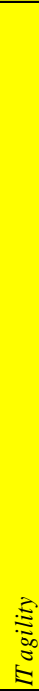 & 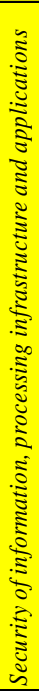 & 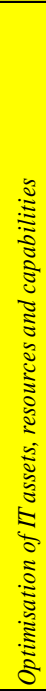 & 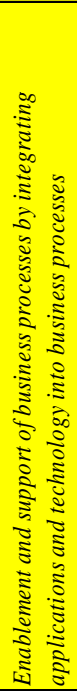 & 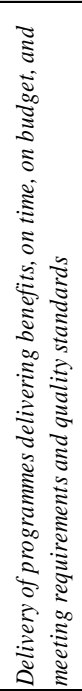 & 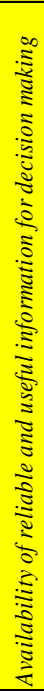 & 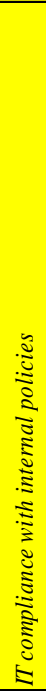 & 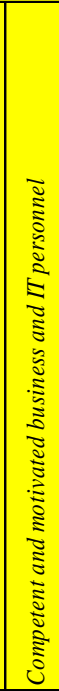 & 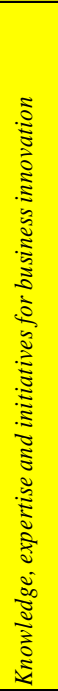 \\
\hline & & & 1 & 2 & 3 & 4 & 5 & 6 & 7 & 8 & 9 & 10 & 11 & 12 & 13 & 14 & 15 & 16 & 17 \\
\hline \multicolumn{3}{|c|}{ COBIT 5 Process } & \multicolumn{6}{|c|}{ Financial } & \multicolumn{2}{|c|}{ Customer } & \multicolumn{7}{|c|}{ Internal } & \multicolumn{2}{|c|}{\begin{tabular}{|c|} 
Learning \\
and Growth
\end{tabular}} \\
\hline \multirow{2}{*}{ 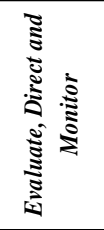 } & EDM03 & $\begin{array}{l}\text { Ensure Risk } \\
\text { Optimisation }\end{array}$ & $\mathbf{S}$ & $\mathbf{S}$ & $\mathbf{S}$ & $\mathbf{P}$ & & $\mathbf{P}$ & $\mathbf{S}$ & $\mathbf{S}$ & & $\mathbf{P}$ & & & $\mathbf{S}$ & $\mathbf{S}$ & $\mathbf{P}$ & $\mathbf{S}$ & $\mathbf{S}$ \\
\hline & EDM04 & $\begin{array}{c}\text { Ensure Resource } \\
\text { Optimisation }\end{array}$ & $\mathbf{S}$ & & $\mathbf{S}$ & $\mathbf{S}$ & $\mathbf{S}$ & $\mathbf{S}$ & $\mathbf{S}$ & $\mathbf{S}$ & $\mathbf{P}$ & & $\mathbf{P}$ & & $\mathbf{S}$ & & & $\mathbf{P}$ & $\mathbf{S}$ \\
\hline 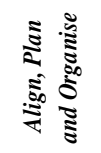 & APO12 & Manage Risk & & $\mathbf{P}$ & & $\mathbf{P}$ & & $\mathbf{P}$ & $\mathbf{S}$ & $\mathbf{S}$ & $\mathbf{S}$ & $\mathbf{P}$ & & & $\mathbf{P}$ & $\mathbf{S}$ & $\mathbf{S}$ & $\mathbf{S}$ & $\mathbf{S}$ \\
\hline 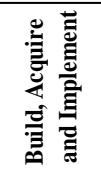 & BAI04 & $\begin{array}{c}\text { Manage } \\
\text { Availability and } \\
\text { Capacity }\end{array}$ & & & & $\mathbf{S}$ & $\mathbf{S}$ & & $\mathbf{P}$ & $\mathbf{S}$ & $\mathbf{S}$ & & $\mathbf{P}$ & & $\mathbf{S}$ & $\mathbf{P}$ & & & $\mathbf{S}$ \\
\hline 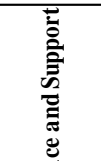 & DSS01 & Manage Operations & & $\mathbf{S}$ & & $\mathbf{P}$ & $\mathbf{S}$ & & $\mathbf{P}$ & $\mathbf{S}$ & $\mathbf{S}$ & $\mathbf{S}$ & $\mathbf{P}$ & & & $\mathbf{S}$ & $\mathbf{S}$ & $\mathbf{S}$ & $\mathbf{S}$ \\
\hline$\stackrel{\overline{0}}{: \overline{0}}$ & DSS03 & Manage Problems & & $\mathbf{S}$ & & $\mathbf{P}$ & $\mathbf{S}$ & & $\mathbf{P}$ & $\mathbf{S}$ & $\mathbf{S}$ & & $\mathbf{P}$ & $\mathbf{S}$ & & $\mathbf{P}$ & $\mathbf{S}$ & & $\mathbf{S}$ \\
\hline 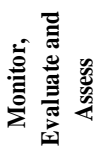 & MEA01 & $\begin{array}{l}\text { Monitor, Evaluate } \\
\text { and Assess } \\
\text { Performance and } \\
\text { Conformance }\end{array}$ & $\mathbf{S}$ & $\mathbf{S}$ & $\mathbf{S}$ & $\mathbf{P}$ & $\mathbf{S}$ & $\mathbf{S}$ & $\mathbf{P}$ & $\mathbf{S}$ & $\mathbf{S}$ & $\mathbf{S}$ & $\mathbf{P}$ & & $\mathbf{S}$ & $\mathbf{S}$ & $\mathbf{P}$ & $\mathbf{S}$ & $\mathbf{S}$ \\
\hline
\end{tabular}




\section{Capability Level}

Untuk menentukan hasil tingkat kapabilitas atau capability level dapat dilakukan dari perhitungan rekapitulasi jawaban responden dari kuesioner dengan menggunakan skala likert yang dapat dijabarkan rumus sebagai berikut :

$$
R K=\frac{\mathrm{C}}{\Sigma \mathrm{R}} \times 100
$$

$$
\begin{array}{lll}
\text { Keterangan } & : & \\
\text { RK } & : & \begin{array}{l}
\text { Rekapitulasi jawaban responden } \\
\text { kuesioner }
\end{array} \\
\mathrm{C} & : & \begin{array}{l}
\text { Hasil banyaknya jawaban untuk setiap } \\
\text { level 0 sampai 5 setiap aktivitas proses }
\end{array} \\
\Sigma \mathrm{R} & : & \text { Jumlah responden }
\end{array}
$$

$$
A K=\frac{\begin{array}{c}
(\mathrm{RK} \times \mathrm{L} 0)+(\mathrm{RK} \times \mathrm{L} 1)+(\mathrm{RK} \times \mathrm{L} 2) \\
100
\end{array}}{\text { (RK x L3) }+(\mathrm{RK} \times \mathrm{L} 4)+(\mathrm{RK} \times \mathrm{L} 5)}
$$

\begin{tabular}{|c|c|c|}
\hline Process & $\begin{array}{c}\text { Index } \\
\text { Capability } \\
\end{array}$ & Level \\
\hline $\begin{array}{l}\text { EDM03 - Ensure Risk } \\
\text { Optimisation }\end{array}$ & 3,11 & $\begin{array}{l}3 \quad \text { (Established } \\
\text { Process) }\end{array}$ \\
\hline $\begin{array}{l}\text { EDM04 - Ensure } \\
\text { Resource Optimisation }\end{array}$ & 3,46 & $\begin{array}{l}3 \quad \text { (Established } \\
\text { Process) }\end{array}$ \\
\hline APO12 - Manage Risk & 2,82 & $\begin{array}{l}3 \quad \text { (Established } \\
\text { Process })\end{array}$ \\
\hline $\begin{array}{lr}\text { BAI04 - } & \text { Manage } \\
\text { Availability } & \text { and } \\
\text { Capacity } & \end{array}$ & 3,32 & $\begin{array}{l}3 \quad \text { (Established } \\
\text { Process) }\end{array}$ \\
\hline $\begin{array}{l}\text { DSS01 - Manage } \\
\text { Operations }\end{array}$ & 3,80 & $\begin{array}{l}4 \quad \text { (Predictable } \\
\text { Process })\end{array}$ \\
\hline $\begin{array}{l}\text { DSS03 - Manage } \\
\text { Problems }\end{array}$ & 3,01 & $\begin{array}{l}3 \quad \text { (Established } \\
\text { Process) }\end{array}$ \\
\hline $\begin{array}{lr}\text { MEA01 }- & \text { Monitor, } \\
\text { Evaluate and } & \text { Assess } \\
\text { Performance } & \text { and } \\
\text { Conformance } & \\
\end{array}$ & 3,75 & $\begin{array}{l}4 \quad \text { (Predictable } \\
\text { Process })\end{array}$ \\
\hline Rata - rata & 3,32 & $\begin{array}{l}3 \quad \text { (Established } \\
\text { Process) }\end{array}$ \\
\hline
\end{tabular}

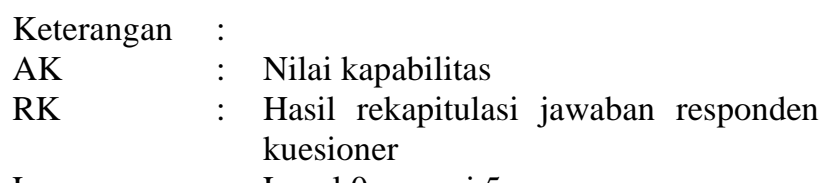

L : Level 0 sampai 5

Dari rumus diatas dapat ditemukan hasil nilai dan tingkat kapabilitas pada proses domain yang sudah terpilih dapat dilihat pada tabel IV.

TABEL IV

Hasil PengukURAn CAPABILITY LeVEL
Hasil perhitungan dari pengukuran tingkat kapabilitas mendapatkan rata - rata nilai pada domain tata kelola TI di Pengadilan Negeri Salatiga Kelas I B adalah 3,32 yang dapat disimpulkan bahwa proses pengelolaan TI dilakukan secara Established Process yang artinya Pengadilan ini sudah menetapkan proses tata kelola TI sehingga dapat mencapai tujuan organisasi. Proses ini didasari dari proses domain domain COBIT 5 terpilih yaitu EDM03 mencapai nilai 3,11 berada di level 3 (Established Process), EDM04 mencapai nilai 3,46 berada di level 3 (Established Process), APO12 mencapai nilai 2,82 berada di level 3 (Established Process), BAI04 mencapai angka 3,32 berada di level 3 (Established Process),DSS01 mencapai nilai 3,80 berada di level 4 (Predictable Process), DSS03 mencapai nilai 3,01 berada di level 3 (Established Process), dan MEA01 mencapai nilai 3,75 berada di level 4 (Predictable Process). Dari domain domain tersebut dapat disimpulkan domain yang mencapai angka tertinggi yaitu DSS01 karena proses domain ini dalam mengelola operasi sudah sangat baik. Kemudian domain yang mencapai angka terendah yaitu APO12 karena proses domain ini masih banyak kekurangan dalam mengelola risiko TI di Pengadilan Negeri Salatiga Kelas I B ini.

\section{E. Analysis Gap}

Analysis gap atau kesenjangan digunakan untuk menentukan langkah apa yang perlu diambil dari kondisi saat ini ke kondisi yang diinginkan. Hal ini diartikan analysis gap digunakan untuk mengevaluasi bisnis di dalam perusahaan pada kesenjangan kinerja saat ini dengan kinerja yang dicapai [16]. Kemudian hasil analisis kesenjangan yang dihitung dari tingkat kapabilitas saat ini (as is) dan target tingkat kapabilitas yang diharapkan (to be), dapat dilihat pada tabel V dan grafik gambar 4.

TABEL V

HASIL ANALISIS GAP

\begin{tabular}{|c|c|c|c|}
\hline Process & As is & To be & Gap \\
\hline EDM03 & 3,11 & 5 & 1,89 \\
\hline EDM04 & 3,46 & 5 & 1,54 \\
\hline APO12 & 2,82 & 5 & 2,18 \\
\hline BAI04 & 3,32 & 5 & 1,68 \\
\hline DSS01 & 3,80 & 5 & 1,20 \\
\hline DSS03 & 3,01 & 5 & 1,99 \\
\hline MEA01 & 3,75 & 5 & 1,25 \\
\hline Rata - rata & 3,32 & 5 & 1,68 \\
\hline
\end{tabular}




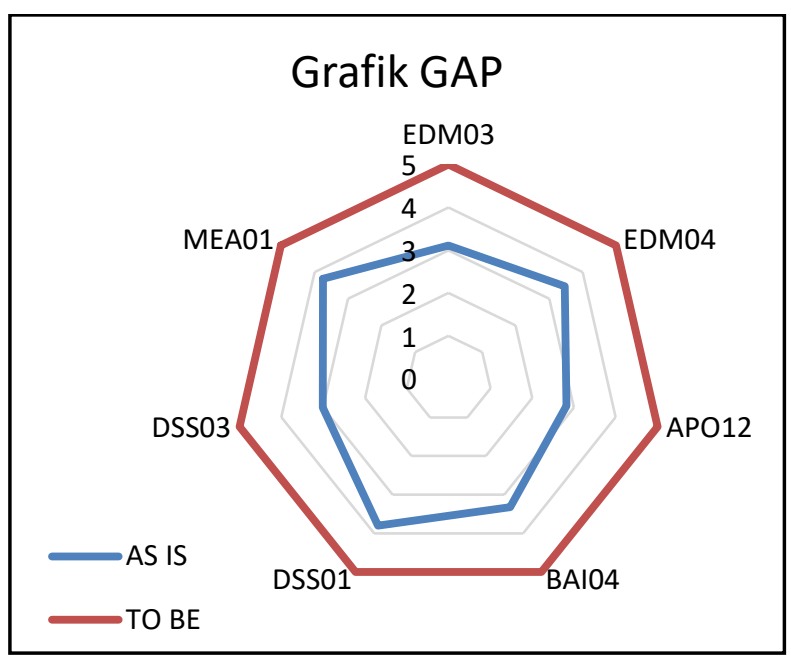

Gambar 4. Grafik Hasil Analisi Gap

Grafik diatas dapat dilihat dari Spider Chart yang disimpulkan bahwa tujuh sub domain proses COBIT 5 yang terpilih belum ada yang mencapai target yaitu level 5 (Optimising Process).

Hasil evaluasi tata kelola TI menunjukan adanya temuan berupa kelebihan dan kekurangan pada sub domain :

1. EDM03 - Ensure Risk Optimisation

Pada bagian optimasi risiko ditemukan bahwa sub bagian TI telah menentukan tingkat risiko. Namun mereka tidak melakukan evaluasi manajemen risiko TI secara rutin dan belum meningkatkan pengawasan risiko TI. Maka rekomendasi yang diberikan yaitu melakukan evaluasi aktivitas manajemen risiko TI secara rutin untuk memastikan kemampuan perusahaan atau organisasi dalam menangani risiko TI dan meningkatkan pengawasan terhadap risiko TI.

\section{EDM04 - Ensure Resource Optimisation}

Pada bagian optimasi sumber daya ditemukan bahwa sub bagian TI telah melakukan evaluasi dan monitoring pada program TI serta peralatan penunjang TI, melakukan pengarahan peralatan penunjang TI dan petugas pengelola TI. Namun, belum dilakukan pengarahan dan evaluasi petugas yang melakukan aktivitas terkait sistem - sistem yang ada terutama pada SIPP. Maka diberikan rekomendasi yaitu melakukan evaluasi serta pengarahan pegawai yang mempunyai akses terhadap sistem - sistem terutama pada SIPP dan e-Court agar dalam menginput data atau mengakses sistem tidak terjadi kesalahan atau keliruan, serta pengarahan dalam penggunaan perangkat lunak seperti Ms. Word dan Ms. Excel.

3. APO12 - Manage Risk

Pada bagian manajemen risiko TI, sub bagian TI telah melakukan identifikasi dan analisis risiko TI namun belum dilakukan klasifikasi risiko TI serta belum sepenuhnya dalam menangani risiko TI. Maka rekomendasi yang diberikan yaitu melakukan klasifikasi risiko TI agar dapat diketahui dari risiko paling tertinggi dan risiko terendah, melakukan laporan hasil analisis risiko TI kepada semua stakeholders, termasuk proses manajemen risiko TI sesuai dengan aturan untuk mendukung keputusan organisasi, melakukan perencanaan dalam aktivitas manajemen risiko TI agar proses berjalan terorganisir dan mengevaluasi risiko TI bagaimana risiko TI dapat diatasi serta melakukan pembagian tugas penanganan risiko TI.

\section{BAI04 - Manage Availability and Capacity}

Pada bagian manajemen kapasitas dan kualitas, sub bagian TI telah menilai kinerja dan kapasitas sistem dalam menciptakan baseline untuk program TI , merencanakan untuk kebutuhan layanan baru atau perubahan program TI dan menilai dampak program TI terhadap kegiatan sumber daya manusia. Namun, sub bagian TI belum mengukur presentasi penggunaan hardware (CPU, memory, printer, dll) dan banyaknya sistem - sistem berbasis website yang menampung dan dapat diakses oleh pengadilan. Maka rekomendasi yang diberikan yaitu Mengukur presentasi penggunaan hardware seperti CPU, memory, printer, dll agar tahu seberapa nilai kemampuan hardware yang digunakan dan menyimpulkan sistem - sistem yang ada dengan cara mengintegrasikan sistem - sistem yang saling terkait.

\section{DSS01 - Manage Operations}

Pada bagian manajemen operasional ditemukan bahwa sub bagian TI telah bekerja berdasarkan standar operasional prosedur atau SOP untuk kegiatan sistem TI, memantau kemampuan TI (hardware dan software) untuk kegiatan yang berhubungan dengan sistem - sistem yang ada, telah memantau kemampuan TI (hardware dan software) untuk kegiatan yang berhubungan dengan sistem - sistem yang ada, telah mengelola fasilitas TI untuk mendukung dan memperlancar kegiatan operasional sistem TI yang ada dan adanya kerjasama dengan tim TI dari pusat atau Mahkamah Agung. Untuk meningkatkan angka target yang diharapkan, maka dapat dilakukan dengan mengoptimalkan pembagian tugas dalam mengelola operasional TI sesuai kedudukan.

\section{DSS03 - Manage Problems}

Pada bagian manejemen masalah TI ditemukan bahwa sub bagian TI telah membuat dokumentasi pencatatan masalah layanan TI, telah menganalisis penyebab dari masalah TI dan program TI, telah memelihara dan meningkatkan kesadaran dan pemahaman pengelolaan masalah TI dan mengukur seberapa efisiensi dan efektivitas pengelolaan masalah dan insiden TI. Namun sub bagian TI belum mengindentifikasi dan mengklasifikasikan permasalahan TI, belum melakukan perencanaan dalam otomatisasi 
proses pengelolaan masalah dan insiden layanan TI. Maka rekomendasi yang dapat diberikan yaitu mengindentifikasi dan klasifikasi permasalahan TI sesuai standarisasi kebijakan prosedur agar dapat mempermudah dalam mengatasi masalah TI, melakukan perencanaan penggunaan perangkat bantu (tools) dan standarisasinya serta otomatisasi proses pengelolaan masalah dan insiden TI serta mengoptimalkan dalam menganalisis permasalahan program TI terutama pada sistem $e$-Court yang paling banyak kekurangan.

7. MEA01 - Monitor, Evaluate and Assess Performance and Conformance

Pada bagian memantau, evaluasi dan menilai sistem dari kendali internal ditemukan bahwa sub bagian TI menggunakan tools dalam memantau kinerja sistem sistem yang ada terutama SIPP, menetapkan tanggung jawab dan kepemilikan dalam memantau dan mengevaluasi kinerja sistem TI dan mengevaluasi kinerja dan kesesuaian target yang ingin dicapai dalam pengelolaan TI. Namun sub bagian TI belum melakukukan pelacakan permasalahan yang terjadi dan kurangnya mengumpulkan data kinerja, proses dan kesesuaian penerapan program TI. Maka rekomendasi yang dapat diberikan yaitu melakukan pelacakan permasalahan TI yang terjadi, ketika permasalahan TI terulang kembali perlu melakukan prosedur baru untuk menyelesaikannya dan mengoptimalkan pengumpulan data kinerja, proses dan kesesuaian penerapan program TI sehingga dapat dioptimalkan program TI.

\section{F. Pengujian Sistem}

Dalam melakukan pengujian e-Court dilakukan pada halaman register dan halaman login menggunakan Blackbox Testing dengan metode Boundary Value Analysis.

\section{Halaman Register}

Hasil pengujian pada halaman register $e$ - Court dapat dilihat pada gambar 5, tabel VI, tabel VII dan tabel VIII.

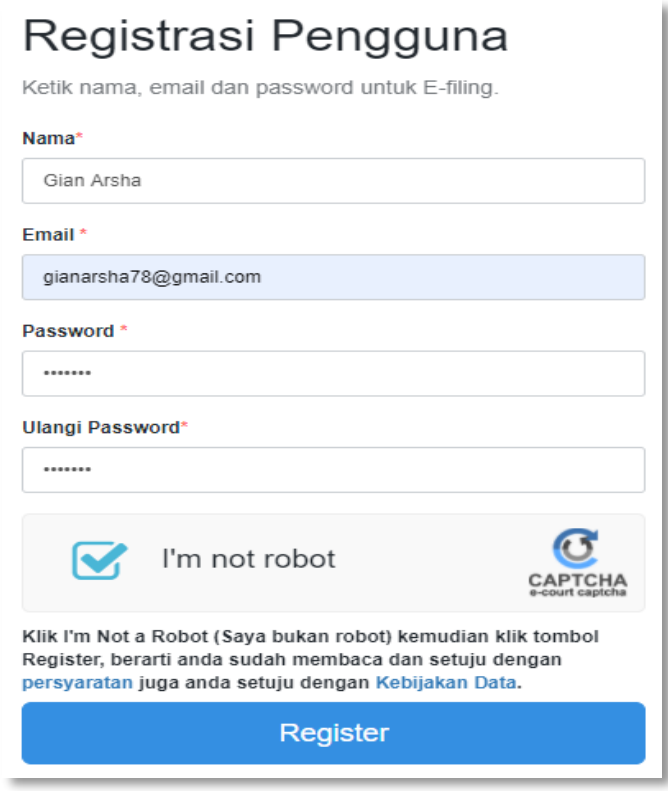

Gambar 5. Halaman Register $e$-Court

TABEL VI

Pengujian Halaman Register Field NAMA

\begin{tabular}{|c|c|c|c|c|}
\hline Field yang dijuji & Skenario Pengujian & Hasil diharapkan & Hasil Uji & Kesimpulan \\
\hline \multirow{3}{*}{$\begin{array}{l}\text { Field Nama } \\
\text { Ketentuan : Field } \\
\text { hanya dapat } \\
\text { berupa huruf dan } \\
\text { wajib diisi }\end{array}$} & $\begin{array}{l}\text { a. Memasukan karakter } \\
\text { "Gian Arsha" }\end{array}$ & $\begin{array}{l}\text { Tidak ada pesan } \\
\text { kesalahan }\end{array}$ & $\begin{array}{l}\text { Tidak ada pesan } \\
\text { kesalahan }\end{array}$ & Sesuai \\
\hline & $\begin{array}{l}\text { b. Memasukan karakter } \\
\text { "Gian Arsha 123" }\end{array}$ & $\begin{array}{l}\text { Ada pesan kesalahan } \\
\text { karena secara umum } \\
\text { nama huruf saja }\end{array}$ & $\begin{array}{l}\text { Tidak ada pesan } \\
\text { kesalahan }\end{array}$ & $\begin{array}{l}\text { Tidak } \\
\text { Sesuai }\end{array}$ \\
\hline & $\begin{array}{l}\text { c. Mengkosongkan pada } \\
\text { field nama }\end{array}$ & $\begin{array}{l}\text { Ada pesan kesalahan pada } \\
\text { field nama }\end{array}$ & $\begin{array}{lr}\text { Ada pesan kesalahan } \\
\text { pada field } & \text { nama } \\
\text { dimana field nama } \\
\text { harus diisi }\end{array}$ & Sesuai \\
\hline
\end{tabular}


TABEL VII

PENGUJian Halaman Register FIELD EMAIL

\begin{tabular}{|c|c|c|c|c|}
\hline Field yang dijuji & Skenario Pengujian & Hasil diharapkan & Hasil Uji & Kesimpulan \\
\hline \multirow{2}{*}{$\begin{array}{l}\text { Field Email } \\
\text { Ketentuan : Field } \\
\text { berupa huruf, } \\
\text { angka dan simbol } \\
\text { dan wajib diisi }\end{array}$} & $\begin{array}{l}\text { a. Memasukan karakter } \\
\text { "gianarsha78@gmail.com" }\end{array}$ & $\begin{array}{l}\text { Tidak ada pesan } \\
\text { kesalahan }\end{array}$ & $\begin{array}{l}\text { Tidak ada pesan } \\
\text { kesalahan }\end{array}$ & Sesuai \\
\hline & $\begin{array}{l}\text { b. Mengkosongkan pada } \\
\text { field email }\end{array}$ & $\begin{array}{l}\text { Ada pesan kesalahan pada } \\
\text { field email }\end{array}$ & $\begin{array}{ll}\text { Ada pesan kesalahan } \\
\text { pada field email } \\
\text { dimana field email } \\
\text { harus diisi }\end{array}$ & Sesuai \\
\hline
\end{tabular}

TABEL VIII

Pengujian Halaman Register Field PASSWORD

\begin{tabular}{|c|c|c|c|c|}
\hline Field yang dijuji & Skenario Pengujian & Hasil diharapkan & Hasil Uji & Kesimpulan \\
\hline \multirow{2}{*}{$\begin{array}{l}\text { Field Password } \\
\text { Ketentuan : wajib } \\
\text { diisi }\end{array}$} & $\begin{array}{l}\text { a. Memasukan karakter } \\
\text { password untuk e-filing } \\
\text { "*******" }\end{array}$ & $\begin{array}{l}\text { Tidak ada pesan } \\
\text { kesalahan }\end{array}$ & $\begin{array}{l}\text { Tidak ada pesan } \\
\text { kesalahan }\end{array}$ & Sesuai \\
\hline & $\begin{array}{l}\text { b. Mengkosongkan pada } \\
\text { field password untuk } e \text { - } \\
\text { filing }\end{array}$ & $\begin{array}{l}\text { Ada pesan kesalahan } \\
\text { pada field password e- } \\
\text { filing }\end{array}$ & $\begin{array}{l}\text { Ada pesan kesalahan } \\
\text { pada field password } \\
e \text {-filing dimana Field } \\
e \text {-filing harus diisi }\end{array}$ & Sesuai \\
\hline \multirow{2}{*}{$\begin{array}{l}\text { Field } \\
\text { Pengulangan } \\
\text { Password } \\
\text { Ketentuan : } \\
\text { passwrord berupa } \\
\text { karakter yang } \\
\text { sama dengan } \\
\text { Password diatas } \\
\text { dan wajib diisi }\end{array}$} & $\begin{array}{l}\text { a. Mengkosongkan pada } \\
\text { field pengulangan } \\
\text { password }\end{array}$ & $\begin{array}{l}\text { Ada pesan kesalahan } \\
\text { pada field pengulangan } \\
\text { password }\end{array}$ & \begin{tabular}{lr}
\multicolumn{2}{l}{ Ada pesan kesalahan } \\
pada & field \\
pengulangan & \\
password dimana \\
password & \\
pengulangan & harus \\
diisi & \\
\end{tabular} & Sesuai \\
\hline & $\begin{array}{l}\text { b. Memasukan karakter } \\
\text { yang berbeda dengan } \\
\text { password diatas }\end{array}$ & $\begin{array}{l}\text { Ada pesan kesalahan } \\
\text { pada field pengulangan } \\
\text { password }\end{array}$ & $\begin{array}{l}\text { Ada pesan kesalahan } \\
\text { pada field } \\
\text { pengulangan } \\
\text { password }\end{array}$ & Sesuai \\
\hline
\end{tabular}

Hasil pengujian yang telah dibuat seperti tabel diatas halaman register $e$-Court pada field nama telah ditemukan ketidaksesuaian yang diharapkan dimana karakter field nama seharusnya berisi karakter huruf yang tipe datanya dengan valid yaitu a-z dan a-z sedangkan 0-9 tidak valid, sedangkan field email dan field password sudah sesuai yang diharapkan.

\section{Halaman Login}

Hasil pengujian pada halaman login umum e-Court dapat dilihat pada gambar 6 dan tabel IX. 


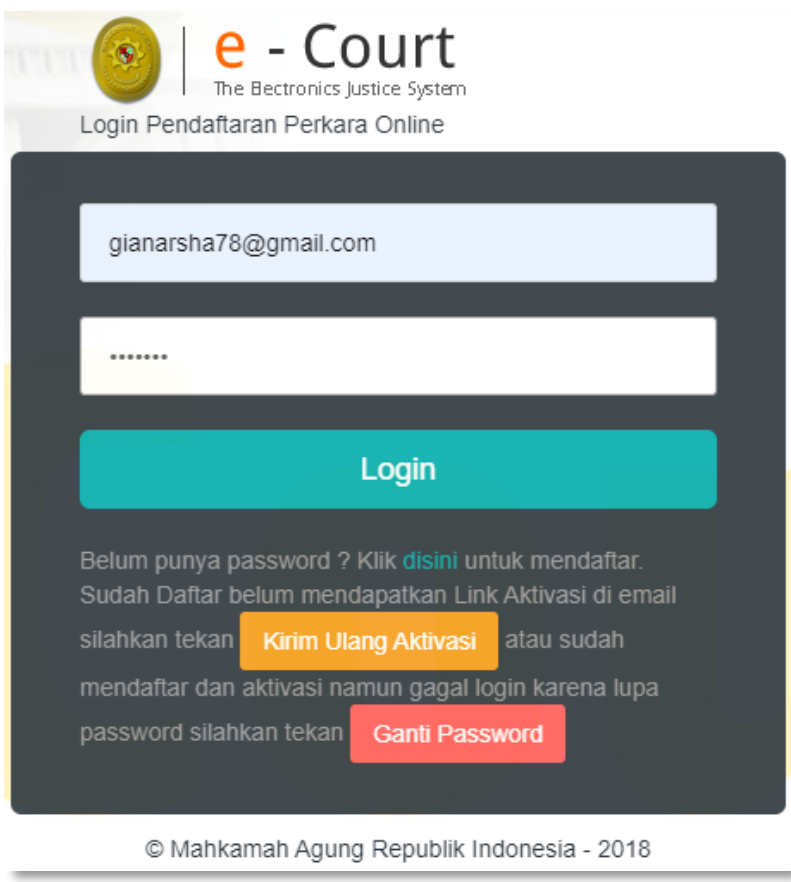

Gambar 6. Halaman Login Umum e-Court

TABEL IX

Pengujian Halaman LOGIN Umum E-COURT

\begin{tabular}{|c|c|c|c|c|}
\hline $\begin{array}{c}\text { Field yang } \\
\text { dijuji }\end{array}$ & Skenario Pengujian & Hasil diharapkan & Hasil Uji & Kesimpulan \\
\hline \multirow{4}{*}{$\begin{array}{l}\text { Field Username } \\
\text { dan } \\
\text { Password } \\
\text { Ketentuan : Field } \\
\text { username berisi } \\
\text { email yang sudah } \\
\text { terdaftar di } \\
\text { register dan field } \\
\text { password berisi } \\
\text { password yang } \\
\text { sudah terdaftar di } \\
\text { register }\end{array}$} & $\begin{array}{l}\text { a. Mengisi field username } \\
\text { "gianarsha78@gmail.com" } \\
\text { dan password "*******" }\end{array}$ & $\begin{array}{l}\text { Login akses diterima dan } \\
\text { masuk pada menu } \\
\text { halaman data advokat }\end{array}$ & $\begin{array}{l}\text { Login akses diterima } \\
\text { dan masuk pada menu } \\
\text { halaman data advokat } \\
\text { dan terdapat nama user } \\
\text { yang sesuai dengan } \\
\text { nama register yaitu } \\
\text { "Gian Arsha" }\end{array}$ & Sesuai \\
\hline & $\begin{array}{l}\text { b. Mengisi field username } \\
\text { "gianarsha78@gmail.com" } \\
\text { dan mengkosongkan field } \\
\text { password }\end{array}$ & $\begin{array}{l}\text { Ada pesan kesalahan } \\
\text { pada field password }\end{array}$ & $\begin{array}{l}\text { Ada pesan kesalahan } \\
\text { pada field password } \\
\text { dimana field password } \\
\text { harus diisi }\end{array}$ & Sesuai \\
\hline & $\begin{array}{l}\text { c. Mengisi field password } \\
\text { "*******" dan } \\
\text { mengkosongkan field } \\
\text { username }\end{array}$ & $\begin{array}{l}\text { Ada pesan kesalahan } \\
\text { pada field username }\end{array}$ & $\begin{array}{l}\text { Ada pesan kesalahan } \\
\text { pada field username } \\
\text { dimana field username } \\
\text { harus diisi }\end{array}$ & Sesuai \\
\hline & $\begin{array}{l}\text { d. Mengisi field username } \\
\text { dan field password yang } \\
\text { tidak terdaftar di register }\end{array}$ & $\begin{array}{l}\text { Login akses ditolak dan } \\
\text { ada pesan kesalahan }\end{array}$ & $\begin{array}{lr}\text { Login akses } & \text { ditolak } \\
\text { dan ada pesan } \\
\text { kesalahan } \\
\text { "usernamelpassword } \\
\text { silakan diisi ulang } \\
\text { kembali" }\end{array}$ & Sesuai \\
\hline
\end{tabular}


Hasil dari pengujian di halaman login umum $e$ Court tidak ditemukan kesalahan fungsionalitas karakter

pada field - field yang artinya semua field sesuai yang diharapkan.

\section{SIMPULAN}

Tata kelola TI di Pengadilan Negeri Salatiga Kelas I B berada pada level 3 (Established Process), hasil kapitulasi dari kuesioner mendapatkan rata - rata domain yang terpilih yaitu mencapai nilai 3,28. Artinya Pengadilan Negeri Salatiga Kelas I B telah melakukan proses pengelolaan TI yang sudah ditetapkan untuk mencapai hasil dari proses pengelolaan TI, ini berarti sub bagian TI menerapkan tata kelola TI dengan baik. Hasil evaluasi yang telah dilakukan ditemukan kelemahan dalam mengelola TI yaitu kurangnya mengelola risiko TI dan masalah TI secara optimal serta terorganisir yang disebabkan kurangnya sumber daya manusia. Dari rentang nilai 0 sampai 5, nilai kondisi diharapkan atau target kedepan yang dipilih yaitu angka 5 dimana proses pengelolaan TI sudah dioptimalkan untuk mencapai tujuan bisnis. Sehingga hasil analisis kesenjangan atau gap yang didapat dari selisih antara kondisi yang diharapkan dengan kondisi saat ini yaitu nilai 1,68. Untuk mencapai angka target yang diharapkan maka dapat mengimplementasikan dari rekomendasi - rekomendasi yang telah diberikan.

Hasil dari pengujian dari salah satu sistem yang dimiliki Pengadilan Negeri Salatiga Kelas I B yaitu $e-$ Court menggunakan metode Blackbox Testing dengan teknik Boundary Value Analysis berfokus pada halaman register dan login. Pada halaman register ditemukan ketidaksesuaian pada field nama yang diharapkan dimana tipe data yang kurang tepat, sehingga perlu diperbaiki tipe data pada field nama yaitu tipe data hanya huruf saja. Pada halaman login semua field sesuai yang diharapkan.

\section{UCAPAN TERIMA KASIH}

Saya ucapkan terimakasih kepada pihak Pengadilan Negeri Salatiga Kelas I B yang telah memberikan ijin dengan senang hati untuk dijadikan sebagai objek penelitian saya. Saya ucapkan lagi kepada teman - teman dan pembimbing saya yang telah mengarahkan saya dalam melakukan penilitian.

\section{DAFTAR PUSTAKA}

J. A. I. Belegur, C. Rudianto, and M. Sitokdana, "Evaluasi Tata Kelola Teknologi Informasi Dinas Pariwisata dan Kebudayaan Kota Ambon Menggunakan Framework Cobit 5.0 pada Domain Monitor, Evaluate And Asses (MEA)," Aiti, vol. 15, no. 2, pp. 107-114, 2018, doi: 10.24246/aiti.v15i2.107-114.

[2] J. W. Lainhart, COBIT 5: A business framework for the governance and management of enterprise IT COBIT 5. 2012.

D. Debiyanti, S. Sutrisna, B. Budrio, A. K. Kamal, and Y. Yulianti, "Pengujian Black Box pada Perangkat Lunak Sistem Penilaian Mahasiswa Menggunakan Teknik Boundary Value Analysis," $J$. Inform. Univ. Pamulang, vol. 5, no. 2, p. 162, 2020, doi 10.32493/informatika.v5i2.5446.

[4] A. Yani, D. Setiawan, N. E. Sofian, R. Subagja, and T. Desyani, "Pengujian Aplikasi Reservasi Hotel di LeGreen Hotel \& Suite dengan Metode Black Box Testing Boundary Value Analysis," $J$ Teknol. Sist. Inf. dan Apl., vol. 3, no. 2, p. 114, 2020, doi: 10.32493/jtsi.v3i2.4686.

[5] Elly and F. Halim, "Evaluasi Tatakelola Infrastruktur Ti Dengan Framework Cobit 5 ( Studi Kasus: Stmik - Stie Mikroskil )," Sebatik, vol. 5, pp. 74-82, 2016.

[6] Y. Fernando, R. Biilmilah, and D. Darwis, "Audit Kinerja Sistem Informasi Penelusuran Perkara Pada Pengadilan Agama Tanjung Karang Kelas I A Bandar Lampung," J. Tekno Kompak, vol. 11, no. 1 , p. 18, 2017, doi: 10.33365/jtk.v11i1.178.

[7] A. K. Darmawan and A. Dwiharto, "Pengukuran Capability Level Kualitas Layanan E-Government Kabupaten Pamekasan Menggunakan Framework COBIT 5.0," INTENSIF J. Ilm. Penelit. dan Penerapan Teknol. Sist. Inf., vol. 3, no. 2, p. 93, 2019, doi: 10.29407/intensif.v3i2.12659.

[8] T. D. Fasilkom, "Tata Kelola Teknologi Informasi," Modul Standar untuk digunakan dalam Perkuliahan di Univ. Mercu Buana, 2017.

[9] G. J. Selig, "IT Governance-An Integrated Framework and Roadmap: How to Plan, Deploy and Sustain for Improved Effectiveness," Gad J.Selig Sch. Eng. Universty Bridg. USA, vol. 25, no. 1, pp. 55-77, 2016

[10] P. Bernard, COBIT 5 A Management Guide, Best Practice. 2017.

[11] A. A. Hamzah, "Buku Panduan e - Court Panduan Pendafataran Online untuk Pengguna Terdaftar," vol. 1, pp. 7-8, 2020, [Online] Available: https://ecourt.mahkamahagung.go.id.

[12] M. Nurudin, W. Jayanti, R. D. Saputro, M. P. Saputra, and Y Yulianti, "Pengujian Black Box pada Aplikasi Penjualan Berbasis Web Menggunakan Teknik Boundary Value Analysis," J. Inform. Univ. Pamulang, vol. 4, no. 4, p. 143, 2019, doi: 10.32493/informatika.v4i4.3841

[13] M. S. Mustaqbal, R. F. Firdaus, and H. Rahmadi, "Pengujian Aplikasi Menggunakan Black Box Testing Boundary Value Analysis (Studi Kasus : Aplikasi Prediksi Kelulusan SNMPTN)," vol. I, no. 3, pp. 31-36, 2015.

[14] Fadila, W. I. Rahayu, and M. H. K. Saputra, Penerapan Metode Naive Bayes dan Skala LIkert Pada Aplikasi Prediksi Kelulusan Mahasiswa. 2020.

[15] P. Jones, "Strategy Mapping for Learning Organizations: Building Agility into Your Balanced Scorecard. Routledge, Abingdon, United Kingdom," 2016

[16] S. Adi, "GAP Analysis (Analisa Kesenjangan)." p. 1, 2015, Accessed: Sep. 04, 2020. [Online]. Available: https://sis.binus.ac.id/2015/07/28/gap-analysis-analisakesenjangan/. 